\title{
PTU-058 ^ 8-YEAR EXPERIENCE OF ENTEROCUTANEOUS FISTULAE AT A NATIONAL INTESTINAL FAILURE CENTRE
}

doi:10.1136/gut.2011.239301.186

G Rahbour, , J Warusavitarne, 1 S M Gabe, ${ }^{2}$ A L Hart, ${ }^{2}$ P Tozer, 1 N Daulatzai, ${ }^{1}$ C J Vaizey ${ }^{1}$ Colorectal and Intestinal Failure Surgery, St. Mark's Hospital and Academic Institute, London, UK; ${ }^{2}$ Department of Gastroenterology, St. Mark's Hospital and Academic Institute, London, UK

Introduction Currently there are two national intestinal failure (IF) centres in England. The treatment of enterocutaneous fistulae (ECF) is complex and challenging. They primarily occur following surgery. Our study examines healing and mortality in ECF patients, with an evaluation of current management practice and outcome.

Methods A retrospective review of ECF in 177 consecutive patients with mean age of 48.7 years (median 49 years) treated over an 8 year period (January 2003-June 2010) in a major tertiary referral centre has been completed. Results have been compared to a previously reported series from this unit of an 11-year experience of 277 patients. $^{1}$

Results Fistulae resulted from surgery in 166 of the 177 patients (93.7\%). 85 of the 177 patients (48.0\%) had a medical history including inflammatory bowel disease (69 Crohn's disease and 16 ulcerative colitis).

150 of the 177 patients underwent definitive surgery (84.7\%). The overall healing rate following surgery in the current series was $94.6 \%$ compared with $82 \%$ in the previous series. Mean delay from previous surgery to current operation was 1 year in the current series compared with 8 months in the previous series. 30 day post fistulae resection mortality was $0 \%$ in this current series compared with $3.5 \%$ in the previous series.

27 of the 177 patients (15.3\%) underwent medical management alone. The overall healing rate following medical management was $46.4 \%$ compared to $19.9 \%$ in the previous series.

In addition to surgical or medical management, Infliximab was used in 5 patients and resulted in fistulae healing in 3.

Conclusion By far the greatest aetiology for ECF formation was surgery performed in patients with a background of inflammatory bowel disease, and more specifically Crohn's disease.

Surgical management of ECF is safe and improving when performed in a dedicated unit and when time is allowed for patient optimisation.

Factors contributing to the improved outcome may include an improved cohesion of our dedicated multidisciplinary team with increasing experience, an increase in mean delay time to

Table 1 PTU-058

Aetiology of ECF form ation

\begin{tabular}{|l|c|c|c|}
\hline & Post operative & Spontaneous & Total \\
\hline Crohn's disease & 59 & 10 & 69 \\
\hline Ulcerative colitis & 16 & 0 & 16 \\
\hline $\begin{array}{l}\text { Previous } \\
\text { Radiotherapy }\end{array}$ & 1 & 0 & 1 \\
\hline $\begin{array}{l}\text { Intra abdominal } \\
\text { malignancy }\end{array}$ & 22 & 1 & 23 \\
\hline Diverticular dise ase & 12 & 1 & 13 \\
\hline Other & 55 & 0 & 55 \\
\hline & $165(93.2 \%)$ & $12(6.8 \%)$ & 177 \\
\hline
\end{tabular}


surgery, insistence that the patient is discharged home prior to surgery wherever possible and improved medical management of Crohn's disease with immunosuppressive and biological drugs.

Competing interests None.

Keywords Enterocutaneous, Fistula, Intestinal Failure.

\section{REFERENCE}

1. Hollington P, Mawdsley J, Lim W, et al. An 11-year experience of enterocutaneous fistula. Br J Surg 2004;91:1646-51. 